\title{
Investigating the mechanism of nanofiltration separation of glucosamine hydrochloride and $\mathrm{N}$-acetyl glucosamine
}

\author{
Shengnan Zhang ${ }^{1,2}$, Jiachun Zhou ${ }^{1}$, Liqiang Fan ${ }^{1}$, Yongjun Qiu ${ }^{1,2}$, Lihua Jiang ${ }^{1 *}$ and Liming Zhao ${ }^{1,2^{*}}$
}

\begin{abstract}
Background: Glucosamine hydrochloride (GAH) and N-acetyl glucosamine (NAG) are chitin derivatives. Owing to their excellent biological activity, they have long been used as pharmaceuticals and nutraceuticals. However, both of them exist simultaneously in chitin hydrolyzate or fermentation production. The aim of this study is to identify the feasibility of separating GAH and NAG by nanofiltration on the basis of appropriate adjustments of physical conditions.

Methods: One commercial spiral nanofiltration membrane (QY-5-NF-1812) was used. Experiments were carried out in full recycle mode and the membrane separation performance was investigated at various mass ratios (mass ratios of GAH to NAG were from 1:14 to 1:2), pressures (4-22 bar), temperatures $\left(15-35^{\circ} \mathrm{C}\right)$, and electrolytes $\left(\mathrm{NaCl}, \mathrm{MgSO}_{4}\right.$, and $\mathrm{MgCl}_{2}$ ). The influence of temperature on molecular characteristics that play an important role in the separation process was also studied.

Results: Owing to the steric-hindrance effect, electrostatic effect, and different solute permeability, the GAH separation factor increased with increasing GAH concentration. Furthermore, upon temperature increasing, the permeability difference between GAH and NAG decreased, thus decreasing the GAH separation factor. Simultaneously, with increasing temperature, the polarities and calculated molecular diameters for both GAH and NAG increased evidently. The calculated reflection coefficients for both GAH and NAG can be well fitted by the steric-hindrance pore (SHP) model, suggesting that steric-hindrance effect played an important role on the separation process. Furthermore, owing to Donnan repulsion and solute diffusion effects, three electrolytes had noticeable effects on nanofiltration separation efficiency.

Conclusions: The nanofiltration separation efficiency of GAH and NAG was significantly affected by their physical properties in this system, and the mechanisms for GAH and NAG separation were elucidated. The current study could provide a certain basis for the nanofiltration separation of GAH and NAG on an industrial scale.
\end{abstract}

\section{Background}

As chitin derivatives, glucosamine hydrochloride (GAH) and $\mathrm{N}$-acetyl glucosamine (NAG) are widespread (Chen et al. 2012). Given that GAH and NAG have significant biological activity and can be used as ligands in coordination chemistry (Tao et al. 2014), both of them have long been used as pharmaceuticals and nutraceuticals to treat

\footnotetext{
*Correspondence: Ihjiang@ecust.edu.cn; zhaoliming@ecust.edu.cn ${ }^{1}$ State Key Laboratory of Bioreactor Engineering, R\&D Center of Separation and Extraction Technology in Fermentation Industry, East China University of Science and Technology, Shanghai 200237, China Full list of author information is available at the end of the article
}

osteoarthritis and maintain cartilage and joint health (Zhu et al. 2015). GAH is usually produced by the $\mathrm{HCl}$ hydrolysis of chitin or fermentation (Zhu et al. 2005a; Chen et al. 2012) and is acidic in aqueous solutions. NAG can be prepared by GAH acetylization or glucose fermentation (Chen et al. 2012; Zhu et al. 2015) and is neutral in aqueous solutions. Both of them exist simultaneously in chitin hydrolyzate or in fermentation production (Deng et al. 2005; Chen et al. 2012). However, since both of them have similar molecular weights (GAH with molecular weight of $215.5 \mathrm{~g} / \mathrm{mol}$ and NAG with molecular weight of $221.0 \mathrm{~g} / \mathrm{mol}$ ) and physical properties, it is 
difficult to separate them from their mixture solutions. Although some monosaccharides can be separated by chromatography (Brereton and Green 2012), the cost of this technique is relatively higher with poor selectivity of an appropriate stationary. Most columns face a number of problems such as column stability, lifetime, and separation reproducibility (Ghfar et al. 2015). Nanofiltration (NF) technology is a good approach for separation due to their advantages, including lower energy consumption, sustainable processing and relatively easy scale-up over other filtration procedures (Kolfschoten et al. 2011; Aroon et al. 2010).

Currently, NF membranes have been applied to many aspects, including the separation of multi-component solution in soybean molasses (Zhao et al. 2013), recycling of phosphoric acid from sewage sludge (Niewersch et al. 2010), recycling wastewater in the dairy industry (Chen et al. 2016), dye removal from aqueous and organic solutions (Kebria et al. 2015), and removal of fermentation inhibitors from wood extracts (Xie and Liu 2015). NF membranes have received increasing attention because of saccharides separation (Dong et al. 2014; Moreno-Vilet et al. 2014).

On the basis of previous research, NF performance can be affected by many factors during separation. Qin et al. (2014) reported that the increase of salt concentrations resulted in rejections for both salt and trisulfonic acid decrease. Sharma et al. (2003) indicated that with increasing temperature, pure water permeability increased because of the increase in polymeric membrane pore size and cutoff size (Desal-5 DL). Wang et al. (2002) demonstrated that the negatively charged membrane showed different rejections for different types of electrolytes with the order of $\mathrm{R}\left(\mathrm{MgSO}_{4}\right)>\mathrm{R}\left(\mathrm{K}_{2} \mathrm{SO}_{4}\right)>\mathrm{R}$ $\left(\mathrm{MgCl}_{2}\right)>\mathrm{R}(\mathrm{KCl})>\mathrm{R}(\mathrm{NaCl})$ as a result of the Donnan and steric-hindrance effects. Sjoman et al. (2007) indicated that different mass ratios significantly influenced the rejections for both xylose and glucose through the steric-hindrance effect. Furthermore, saccharides, such as pectate oligosaccharides (which are acidic in aqueous solutions), carry an electric charge that affect their separation by NF membranes (Iwasaki and Matsubara 2000).

However, the possibilities of NF separations for monosaccharides with similar molecular weights have seldom been studied, and the transport mechanisms for monosaccharides are not fully understood. From the traditional point of view, membrane filtration would require a tenfold difference in molar mass or threefold difference in hydrodynamic radius for separation of components from each other (Sjoman et al. 2007). Simultaneously, many mathematical models have been proposed to describe and predict the process of NF. Generally, the filtration mechanisms involve mainly steric hindrance (Bowen et al. 1997), Donnan exclusion (Schaep et al. 2001), and dielectric exclusion effects (Yaroshchuk 2001). Nevertheless, the NF separation mechanisms for mixed monosaccharides with similar molecular weights were seldom studied and many of them focused on the study of neutral monosaccharides, such as xylose and glucose (Sjoman et al. 2007). Different from neutral monosaccharides, GAH is one kind of the cationic monosaccharides and the molecular weights of GAH and NAG are similar.

Thus, the aim of this study is to identify the feasibility of separating GAH and NAG using NF by regulating and controlling physical conditions, including different mass ratios, pressures, temperatures, and three types of electrolytes. Thereafter, the separation performance is evaluated by a series of models to lay the foundation for large-scale industrial utilization of monosaccharide purification with the same or similar molecular weights. Furthermore, varying molecular characteristics such as the changing molecular diameters and polarities caused by temperature are also investigated to obtain an insight into the processing of glucosamine fractions separation.

\section{Theories}

A series of models used for describing the membrane separation performance and molecular characteristics are explored as follows:

\section{Concentration polarization model}

Generally, the solute rejection performance is estimated by the observed rejection:

$$
R_{\mathrm{o}}=1-\frac{C_{\mathrm{p}}}{C_{\mathrm{b}}}
$$

where $C_{\mathrm{p}}$ and $C_{\mathrm{b}}$ are the solute concentrations in the permeate and bulk feed, respectively. However, given the effect of concentration polarization, which decreases driving force, the solute concentration $C_{\mathrm{m}}$ on the membrane surface is higher than that in the bulk solution because of the reversible accumulation of the rejected solute when the permeate flux is large. Therefore, the real rejection $R$ is defined as follows to represent the rejection ability of membranes:

$$
R=1-\frac{C_{\mathrm{p}}}{C_{\mathrm{m}}}
$$

The relation between the observed retention and the real retention can then be obtained (Wang and Chung 2005):

$$
\ln \left(\frac{1-R_{\mathrm{o}}}{R_{\mathrm{o}}}\right)=\ln \left(\frac{1-R}{R}\right)+\frac{J_{\mathrm{v}}}{k}
$$


Equation (3) can be used with an appropriate mass transport model for the membrane to determine the membrane parameters and mass transfer coefficient $k$.

\section{Irreversible thermodynamic model}

Kedem and Katchalsky (1958) proposed the following transport equations to describe the permeating process via the membrane on the basis of non-equilibrium thermodynamics: the permeate flux $J_{\mathrm{v}}$ is expressed as follows:

$$
J \mathrm{v}=L_{\mathrm{p}}(\Delta P-\Delta \pi)
$$

where $L_{\mathrm{p}}$ is the pure water permeability of the membrane, $\Delta P$ is called the trans-membrane pressure, and $\Delta \pi$ is the osmotic pressure difference across the membrane.

According to the Hagen-Poiseulle (HP) equation, Eq. (4) can be defined as follows (Bowen et al. 1997):

$$
\frac{J_{\mathrm{v}}}{(\Delta P-\Delta \pi)}=\frac{r_{\mathrm{p}}^{2}}{8 \mu\left(\Delta x / A_{\mathrm{k}}\right)}
$$

where $\Delta x / A_{\mathrm{k}}, r_{\mathrm{p}}$, and $\mu$ are the ratio of the effective membrane thickness to membrane porosity, the mean pore radius of the membrane, and the solute viscosity, respectively. Thus, the membrane structural changes including $\Delta x / A_{\mathrm{k}}$ and $r_{\mathrm{p}}$ can be determined by experimental data.

An irreversible thermodynamic Spiegler-Kedem model (Spiegler and Kedem 1966) was applied to explain the separation performance of no electrostatic interaction between membrane and solute. This case occurs when the membrane is uncharged or the solute is neutral. This model has been extended (Koter 2006; Mehiguene et al. 1999) to describe the retention of electrolyte with a charged NF membrane. The working equations of the nonlinear Spiegler-Kedem model are as follows:

$$
R=1-\frac{C_{\mathrm{p}}}{C_{\mathrm{m}}}=\frac{\sigma(1-F)}{1-\sigma F}
$$

with

$$
F=\exp \left(-\left((1-\sigma) / P_{\mathrm{s}}\right) J_{\mathrm{v}}\right)
$$

where the reflection coefficient $\sigma$ represents the separation capability of a membrane, and $P_{\mathrm{s}}$ is the solute permeability.

According to Murthy and Chaudhari (2009), the substitution of Eq. (6) into Eq. (3) results in the following equation:

$$
\frac{1-R_{\mathrm{o}}}{R_{\mathrm{o}}}=\frac{1-\sigma}{\sigma} \frac{\exp \left(\frac{J_{\mathrm{v}}}{k}\right)}{1-\exp \left(-\frac{(1-\sigma) J_{\mathrm{v}}}{P_{\mathrm{s}}}\right)}
$$

Using a nonlinear parameter estimation method and the data of $R_{\mathrm{o}}$ vs. $J_{\mathrm{v}}$ taken at different pressures but at constant feed rates and feed concentrations for each set, some parameters that represent membrane separation performance such as $\sigma, P_{\mathrm{s}}$, and $k$ can be estimated simultaneously.

\section{Calculation of the molecular diameter}

However, the irreversible thermodynamic model is just related to the changes in the membrane structure and it is not related to the changes in the molecular structure. To observe the variation of molecular size with temperature change, the molecular diameter and energetic optimization procedure is conducted via an iterative procedure using the computer program HyperChem (Van der Bruggen et al. 1999). The molecular energy is also minimized by adjusting the configuration of the molecules. In this way, a complete view of the molecular structure and shape can be obtained. The smallest cuboid [including the smallest length (a), width (b), and height (c)] around the molecule is then determined (Fig. 1A, B). The minimum cross-sectional diameter $d_{\mathrm{c}}$ is then calculated as follows:

$$
d_{\mathrm{c}}=\left(b^{2}+c^{2}\right)^{0.5}
$$

The research in this study found that the pressure, feed concentration and ion strength hardly have influence on the calculated molecular diameter but the temperature has some influence on the calculated molecular diameter.

Simultaneously, molecular polarity can be obtained from HyperChem.

\section{Steric-hindrance pore model}

To verify the simulation correctness by the HyperChem, the steric-hindrance pore model in this study is introduced. Nakao and Kimura (1982) proposed the sterichindrance pore (SHP) model by modifying the pore model as follows:

$$
\sigma=1-\left(1+\frac{16}{9} \lambda^{2}\right)(1-\lambda)^{2}\left[2-(1-\lambda)^{2}\right]
$$

with

$$
\lambda=\frac{r_{\mathrm{s}}}{r_{\mathrm{p}}}
$$

In Eq. (10), $r_{\mathrm{s}}$ represents the solute radius and $r_{\mathrm{p}}$ represents the mean pore radius of the membrane. Here, $r_{\mathrm{s}}$ can be substituted by $d_{\mathrm{c}} / 2$. Therefore, $\sigma$ can also be calculated using the molecular diameter and the membrane pore radius. By observing the relationship between the reflection coefficient obtained from the irreversible thermodynamic model and that obtained from the sterichindrance pore model, the simulation correctness can be verified. 


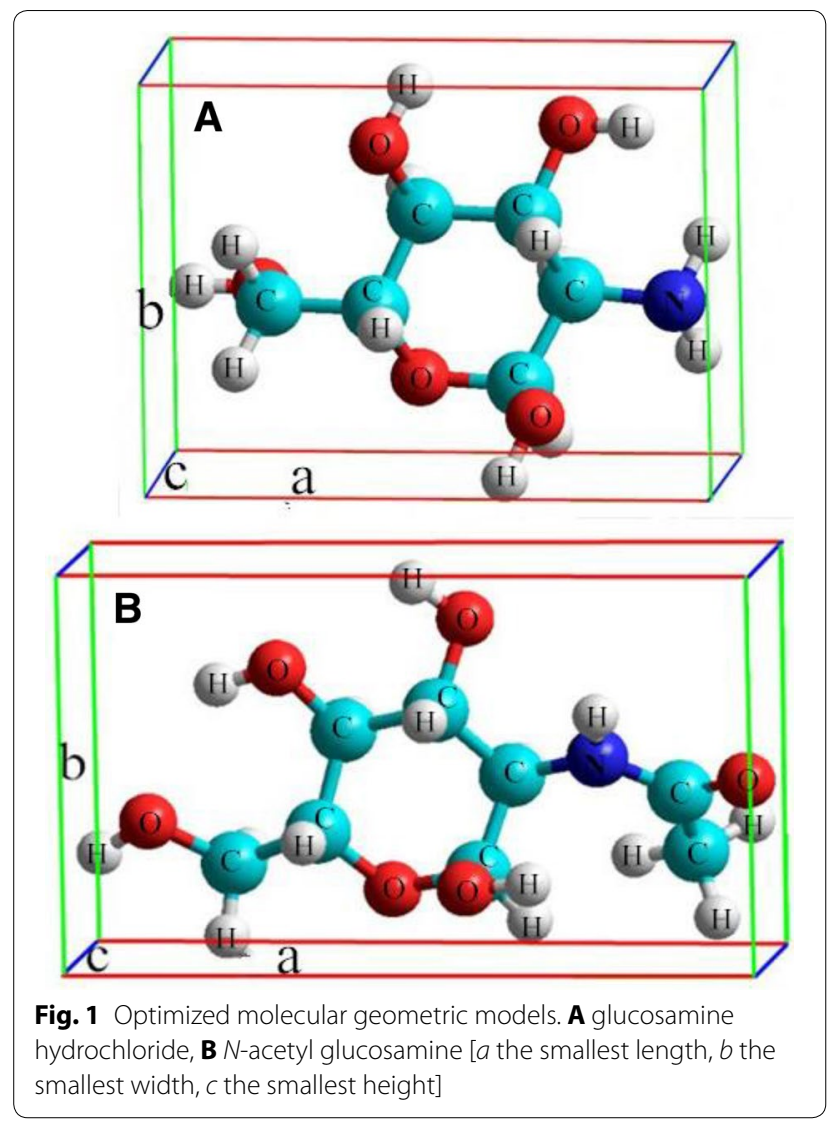

\section{Methods}

\section{Nanofiltration membrane}

The commercial spiral wound NF membrane QY5-NF-1812 was supplied by AMFOR Inc., Newport Beach, United States. A 1812 type module has a 1.8 inch $(4.6 \mathrm{~cm})$ cross-section diameter and 12 inch $(30.5 \mathrm{~cm})$ length. The selective layer of the composite membrane was made of polyamide polymers that are negatively charged on the surface. The maximum temperature tolerance was $45{ }^{\circ} \mathrm{C}$, and a $\mathrm{pH}$ of 4-12 was allowed. Furthermore, the molecular weight cutoffs (MWCO) of the membrane was measured by polyethylene glycols. According to the definition of MWCO, the approximate MWCO of the membrane was $500 \mathrm{Da}$. Further information about the NF membrane is listed in Table 1. Given the larger MWCO compared with the MWCO of 200, rejections for salts were lower and retentions for monovalent salts were lower than those for divalent salts.

\section{Chemicals and reagents}

GAH and NAG were of analytical grade and purchased from Shandong Aokang Biotechnology Co. Ltd. (Shandong, China) and Zhejiang Aoxing Biotechnology Co. Ltd. (Zhejiang, China), respectively. Several analytical
Table 1 Membrane information

\begin{tabular}{lc}
\hline Membrane index & Parameter \\
\hline Type & 1812 \\
MWCO (Da) & 500 \\
Max. Pressure (bar) & 40 \\
Pure water permeance $\left(\mathrm{L} \mathrm{m}^{-2} \mathrm{~h}^{-1} \mathrm{bar}^{-1}\right)^{\mathrm{a}}$ & $11-13$ \\
$\mathrm{MgSO}_{4}$ retention (\%) & 50 \\
$\mathrm{Na}_{2} \mathrm{SO}_{4}$ retention $(\%)^{\mathrm{b}}$ & 85 \\
$\mathrm{NaCl}^{\mathrm{b}}$ retention $(\%)^{\mathrm{b}}$ & 15 \\
$\mathrm{CaCl}_{2}$ retention (\%) & 10 \\
\hline
\end{tabular}

a test condition: 5 bar, $25^{\circ} \mathrm{C}$

b test conditions: $2000 \mathrm{mg} / \mathrm{L}, 4.8 \mathrm{bar}, 25^{\circ} \mathrm{C}$

grade salts, namely, $\mathrm{MgSO}_{4}, \mathrm{Na}_{2} \mathrm{SO}_{4}, \mathrm{NaCl}, \mathrm{MgCl}_{2}$, $\mathrm{CaCl}_{2}, \mathrm{NaOH}$, and EDTA (ethylene diamine tetraacetic acid), were supplied by Lingfeng Chemical Reagent Co. Ltd. (Shanghai, China). The deionized water (conductivity $\leq 10 \mu \mathrm{S} \mathrm{cm}^{-1}$ ) used for experiments and cleaning was supplied by Shanghai Huazhen Co. Ltd. (Shanghai, China).

\section{Permeation experiments}

Figure 2 illustrates the schematic of the setup for the NF experiment. The membrane was initially flushed with deionized water for $30 \mathrm{~min}$ to remove possible contaminants. In the experiments of NF, the total concentration of the feed was maintained at $7.5 \mathrm{wt} \%$, and $2.0 \mathrm{~L}$ syrup was added into the feed bank. The permeate experiments were conducted under the conditions of the applied pressures of 4-22 bar, and the pressure increased at a gradient of 3 bar. On the above cases, serial conditions were operated while only one factor was changed each time. The mass ratios of GAH to NAG in the solutions were 1:2 (solution $\mathrm{pH}$ was 4.18 that was close to $\mathrm{pH}$ tolerance of the membrane) and 1:4/1:14, respectively. The temperatures varied from 15 to $35^{\circ} \mathrm{C}$, and the temperature in the gradient increased to $5^{\circ} \mathrm{C}$. Subsequently, $\mathrm{NaCl}, \mathrm{MgCl}_{2}$, or $\mathrm{MgSO}_{4}$ was added into the syrup. The concentrations of the salts were $0.08 \mathrm{~mol} / \mathrm{L}$. The feed flow rate was maintained at $5.4 \mathrm{~L} / \mathrm{min}$. All penetrates and all retentates were recycled in the feed tank to make the feed concentration constant. After each experiment, the equipment was cleaned by $0.3 \mathrm{~g} / \mathrm{L} \mathrm{NaOH}$ and $0.4 \mathrm{~g} / \mathrm{L}$ EDTA.

\section{Analysis methods}

The conductivity was measured by an electric conductivity meter (Shanghai Jingke, DDS-307, China), and the viscosity was measured by Ubbelohde Viscometer. The solution $\mathrm{pH}$ was measured by the FE20 pH meter (Mettler Toledo, Shanghai, China). The GAH and NAG contents of the samples were analyzed by the HPLC method 


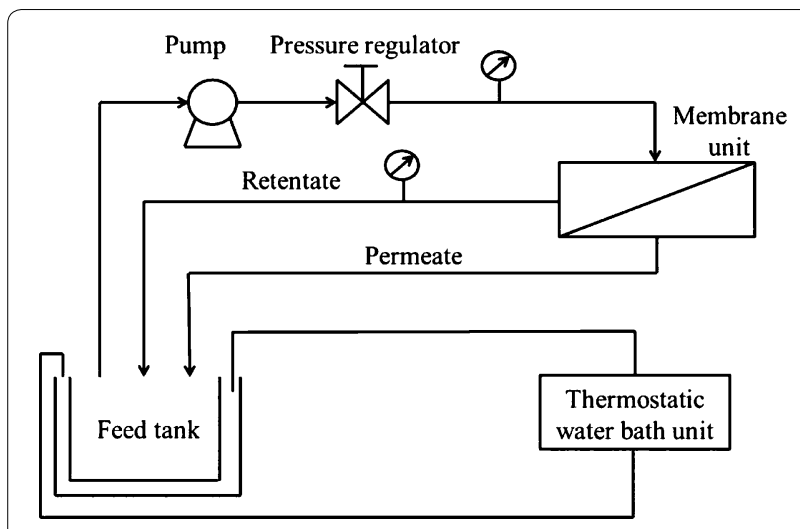

Fig. 2 Schematic representation of the nanofiltration unit

(Agilent 1200, Agilent, USA) equipped with a high-performance sugar column (Sugarpak-I column, Waters, USA) and an RI detector.

The GAH separation factor $S_{\mathrm{GAH}}$ is a measure of GAH purification from NAG. This factor indicates the change in the permeate composition compared with the original ratio of GAH to NAG in the feed. The separation can be achieved if the separation factor differs from unity. A value higher than one indicates a GAH enrichment in the permeate and higher separation factor means better separation performance. Sjoman et al. (2007) showed that during the xylose and glucose separation process by NF, because of their difference in molecular weights, the xylose separation factor could increase from 1.2 to 2.3 by changing physical conditions. The GAH separation factor is defined as follows:

$$
S_{\mathrm{GAH}}=\frac{C_{\mathrm{p}, \mathrm{GAH}} / C_{\mathrm{p}, \mathrm{NAG}}}{C_{\mathrm{b}, \mathrm{GAH}} / C_{\mathrm{b}, \mathrm{NAG}}}=\frac{1-R_{\mathrm{GAH}}}{1-R_{\mathrm{NAG}}}
$$

where $C_{\mathrm{p}, \mathrm{GAH}}, C_{\mathrm{p}, \mathrm{NAG}}$ are the concentrations of $\mathrm{GAH}$ and NAG in permeate, and $C_{\mathrm{b}, \mathrm{GAH}}, C_{\mathrm{b}, \mathrm{NAG}}$ are the concentrations of GAH and NAG in bulk feed, respectively.

\section{Results and discussion}

Influence of different mass ratios on separation performance

\section{Influence of different mass ratios on feed volume flux}

Figure 3 displays that for every mass ratio, the volume flux as a function of the applied pressure can be plotted as a nearly linear line with a wide range of mass ratios. This result is in accordance with the Speigler-Kedem model. As shown in Eq. (4), the flux is approximately proportional to the trans-membrane pressure. However, the slope deviation from linearity occurs at the higher pressures, particularly in the case of GAH:NAG with 1:14 because of the concentration polarization exacerbated owing to NAG accumulation at the membrane surface

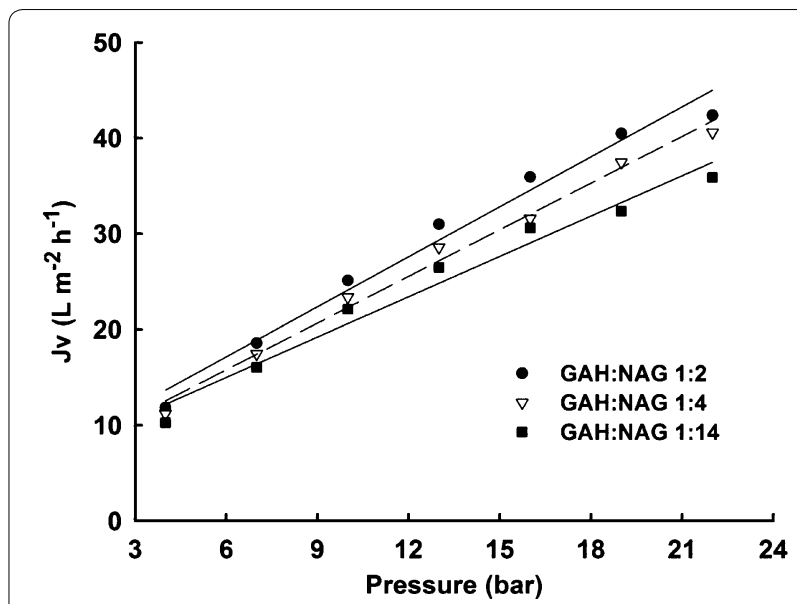

Fig. 3 Effect of different pressures and mass ratios on volume flux. It was operated under the condition of total mass of $7.5 \mathrm{wt} \%$ and the temperature of $25^{\circ} \mathrm{C}$

by the driving pressure. Feed flux increases with increasing GAH:NAG ratio. This observation is influenced by the effective membrane thickness (Bargeman et al. 2014). Given that the electric double layer is compressed with higher salt concentrations, the effective membrane thickness becomes thinner (Table 2). Table 2 also shows that the osmotic pressure difference varied insignificantly. However, the pore radius decreases from 0.632 to $0.615 \mathrm{~nm}$ with increasing GAH:NAG ratio. This phenomenon is caused by the skin shrinkage (Freger et al. 2000) owing to the placement of GAH in an aqueous solution. This result is in agreement with that of Qin et al. (2014).

\section{Rejection difference between single solution and mixed solution}

To have a full study on the separation performance for glucosamine derivatives and achieve good separation results, the rejection difference between a single solution (only one solute comprising: GAH or NAG) and mixed solution (containing two solutes: GAH and NAG) is observed. As shown in Fig. 4a, compared with single solution, at the same solute concentration and pressure, the rejections of GAH decrease in the mixed solution. The results are mainly affected by the addition of NAG. The addition of the NAG solution into the GAH solution leads to the increase of solution viscosity. For example, the viscosity of single GAH solution with the concentration of $2.5 \mathrm{wt} \%$ is $0.91 \mathrm{mPa} \mathrm{s}$ and increases to $1.01 \mathrm{mPa} \mathrm{s}$ in a mixed solution at the same GAH concentration. The solute concentration on the membrane is thicker than the one in the feed that aggravates the concentration polarization. Thereby, the solute concentration accelerates GAH diffusion from the concentration side to the 
Table 2 Estimated pore radius $\left(r_{p}\right)$, osmotic pressure difference $(\Delta \pi)$ and effective thickness $\left(\Delta x / A_{k}\right)$

\begin{tabular}{llll}
\hline Different mass ratios & $\boldsymbol{R}_{\boldsymbol{p}}(\mathrm{nm})$ & $\boldsymbol{\Delta} \boldsymbol{\pi}(\mathrm{bar})$ & $\boldsymbol{\Delta} \boldsymbol{x} / \boldsymbol{A}_{\boldsymbol{k}}(\boldsymbol{\mu m})$ \\
\hline $1: 2$ & 0.615 & 0.2001 & 1.93 \\
$1: 4$ & 0.623 & 0.2002 & 2.00 \\
$1: 14$ & 0.632 & 0.2001 & 2.35 \\
\hline
\end{tabular}
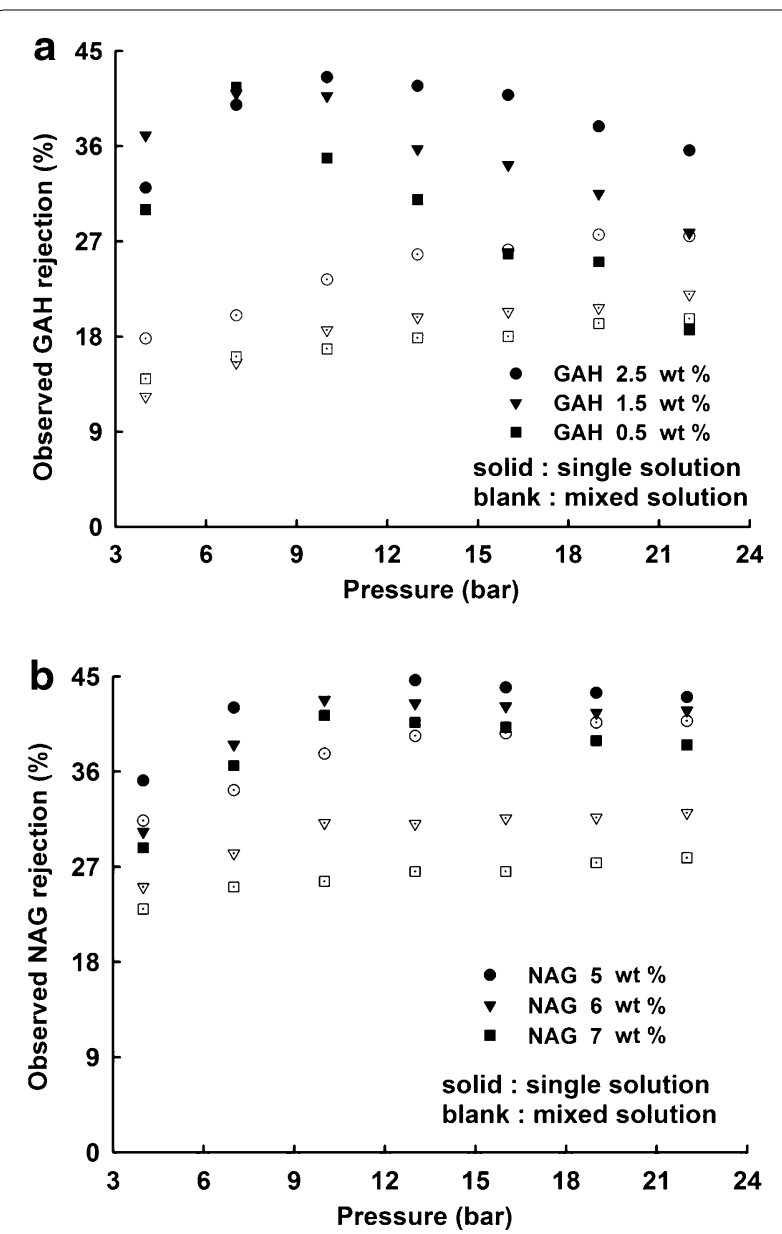

Fig. 4 The rejection difference between single solution and mixed solution. a The difference for $\mathrm{GAH}$ rejections, $\mathbf{b}$ the difference for NAG rejections (temperature of $25^{\circ} \mathrm{C}$, operating pressure of $4-22$ bar)

penetration side. Hence, GAH rejections decrease in the mixed solution compared with a single solution. Simultaneously, the rejection of a single GAH solution with increasing pressure tends to decrease. With increasing pressure, large amounts of $\mathrm{RNH}_{3}{ }^{+}$(here $\mathrm{R}$ represents $\left.\mathrm{C}_{6} \mathrm{H}_{11} \mathrm{O}_{5}\right)$ accumulate on the negatively charged membrane surface. This phenomenon reduces the effective charge density of the NF membrane, thus decreasing the repulsive force for $\mathrm{Cl}^{-}$. According to the Donnan effect, more positive ions permeate the membrane. Hence, the dropping trend of the observed GAH rejection occurs at a high pressure range.

Figure $4 \mathrm{~b}$ illustrates that compared with single solution, the NAG rejection in the mixed solution decreases; this result is consistent with that of Luo and Wan (2011). One reason is a partial dehydration of solute because the "salting-out" effect (also called the Hofmeister effect [Kunz et al. 2004)] causes a decrease of solute hydrodynamic radius, thus inducing a decrease in solute retention. Another reason is that, at a higher GAH concentration, the membrane becomes more compacted than that with a lower GAH concentration (Bargeman et al. 2014). Correspondingly, the double electric layer becomes compressed, leading to the thinner double electric layer and the increase of the channel in the membrane pore. Therefore, NAG rejection decreases in the mixed solution.

\section{Influence of different mass ratios on GAH separation factor}

According to Eq. (12), the GAH separation factor can be obtained. The results indicate that different mass ratios have an important effect on the separation of GAH and NAG. Figure 5a shows that the GAH separation factors at higher GAH concentrations are larger than those at lower GAH concentrations. The maximum GAH separation factor is up to 1.23 at the mass ratio of $1: 2$ and pressure of 10 bar. Different from mass ratios, the separation of the two monosaccharides depends weakly on trans-membrane pressures. At every proportion, the separation factor changes slightly even at a relatively stable value when the pressure increases from 4 to 22 bar. Compared to Fig. 5a, b exhibits the retention difference values between GAH and NAG. Remarkably, at the mass ratio of $1: 2$, the retention difference value between $\mathrm{GAH}$ and NAG is the biggest, and the maximum value is up to $14.3 \%$ at the pressure of $10 \mathrm{bar}$.

The above results can be attributed to the following explanations: both the MWCO and molecular diameter [obtained from Eq. (9)] of GAH are smaller than NAG (at $25{ }^{\circ} \mathrm{C}$, the molecular diameters for GAH and NAG are 0.61 and $0.67 \mathrm{~nm}$, respectively). Therefore, the $\mathrm{GAH}$ rejection is smaller than NAG rejection because of the steric-hindrance effect (Sjoman et al. 2007). Furthermore, the positive charge of GAH can interact with the negative charge at the membrane surface because of electrostatic attraction, which reduces the electric quantity on membrane surface and diminishes the dielectric effect of the membrane (Qin et al. 2014). This result promotes that GAH penetrates the membrane. Different from GAH, neutral NAG cannot interact with the membrane, under the effect of steric hindrance, so GAH is less rejected than NAG. Furthermore, the permeability [obtained from Eq. (8)] of GAH and NAG is apparently different. As 

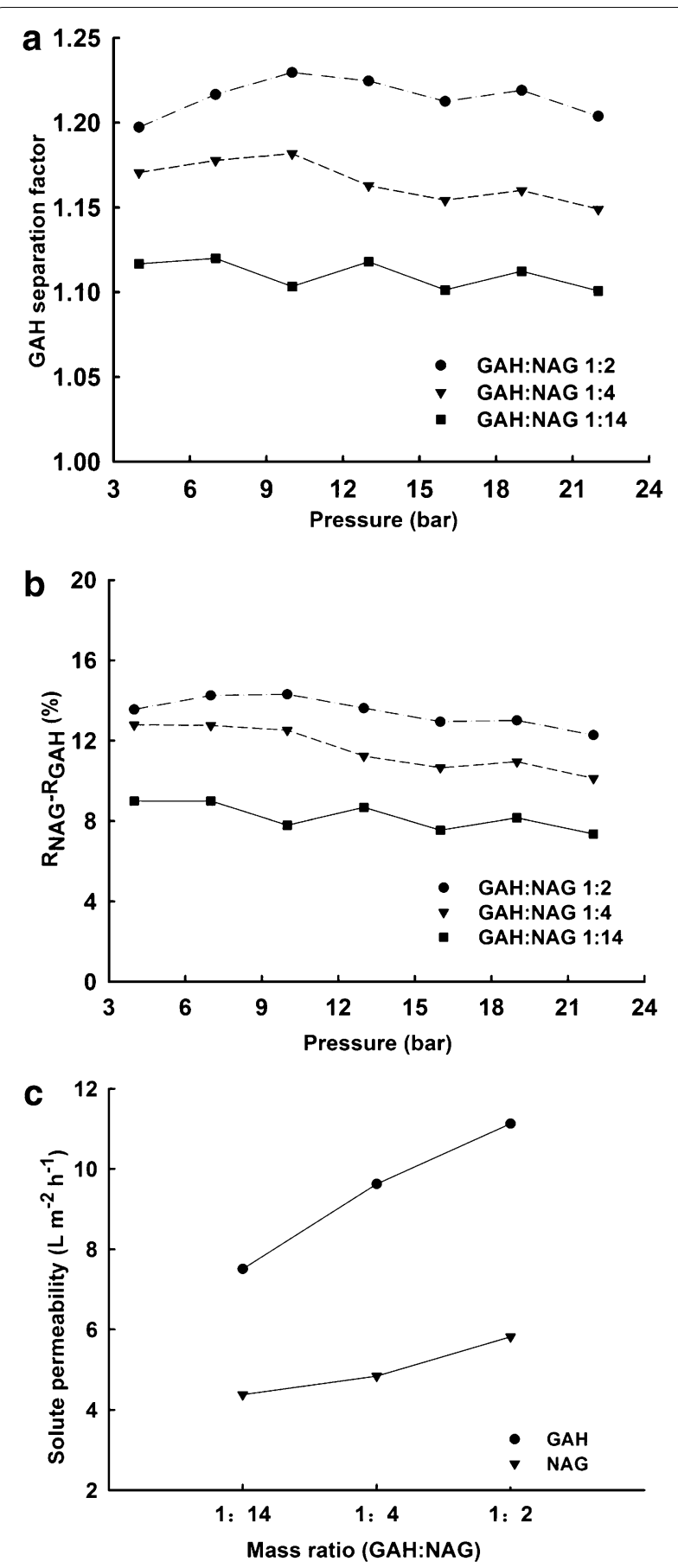

Fig. 5 Effects of different pressures and mass ratios on a GAH separation factor, $\mathbf{b}$ difference value between observed GAH and NAG retentions, c solute permeability of GAH and NAG. The experiments were operated under the condition of total mass of $7.5 \mathrm{wt} \%$ and the temperature of $25^{\circ} \mathrm{C}$

shown in Fig. 5c, GAH permeability is larger than NAG permeability at every mass ratio, and the permeability difference value is larger at higher GAH concentrations.
Therefore, given the influence of permeability, MWCO, molecular diameter, and electrostatic effect, the rejection of GAH is less than NAG rejection, and the separation performance presents different results with different mass ratios. On the basis of the above results, the mass ratio of 1:2 (GAH:NAG) has been chosen in the next experiments.

\section{Influence of different temperatures on separation performance Influence of different temperatures on rejections for GAH and NAG and feed volume flux}

Figure $6 \mathrm{a}, \mathrm{b}$ shows that both GAH and NAG rejections decrease with increasing temperature. This phenomenon can be concluded by the following reasons. Firstly, the solution viscosity is an important factor (Bui and Nguyen 2004). Figure 7 a shows that feed viscosity decreases from 1.17 to $0.88 \mathrm{mPa} s$ when the temperature increases from $15-35{ }^{\circ} \mathrm{C}$. According to Zhu et al. (2005b), the reducing viscosity leads to the increasing diffusibility of the solute to cause the mass transfer coefficient increase. Secondly, the variations of the membrane structural property, such as pore radius with increasing temperature, can account well for the temperature dependence (Ben Amar et al. 2009). With increasing temperature, the membrane pore radius increases from 0.52 to $0.66 \mathrm{~nm}$ (Fig. 7b), also benefiting the solute diffusion. Simultaneously, by considering the changing feed viscosity and pore radius caused by temperature, all solutes in the process preferred to move to the bulk part of the syrups, thus reducing the rate of concentration polarization and improving the membrane flux (Fig. 6c). Furthermore, the solute dipole moment is significantly influenced by increasing temperature (Fig. 8a). According to Van der Bruggen et al. (1999), the side of the dipole with the opposite charge is close to the membrane. The dipole is directed towards the pore and enters easily into the membrane structure. Given that the entry in the membrane structure is facilitated, higher dipole moment leads to lower retention.

\section{Influence of different temperatures on molecular characteristics}

The temperature influences not only the NF membrane but also the molecular characteristics (Jian et al. 2015; Paul and Paul 2015; Xing et al. 2013). Therefore, temperature plays an important part in the NF process. Figure 8a, b illustrates the effects of temperature on the molecular polarities and calculated diameters. Figure 8a shows that the GAH dipole moment increases from 3.54 to 3.74 Debye with increasing temperature from $15-35^{\circ} \mathrm{C}$. Compared with GAH, the dipole moment of NAG increases rapidly and the maximum dipole moment is up to 5.94 Debye when the temperature reaches $35^{\circ} \mathrm{C}$. The results 

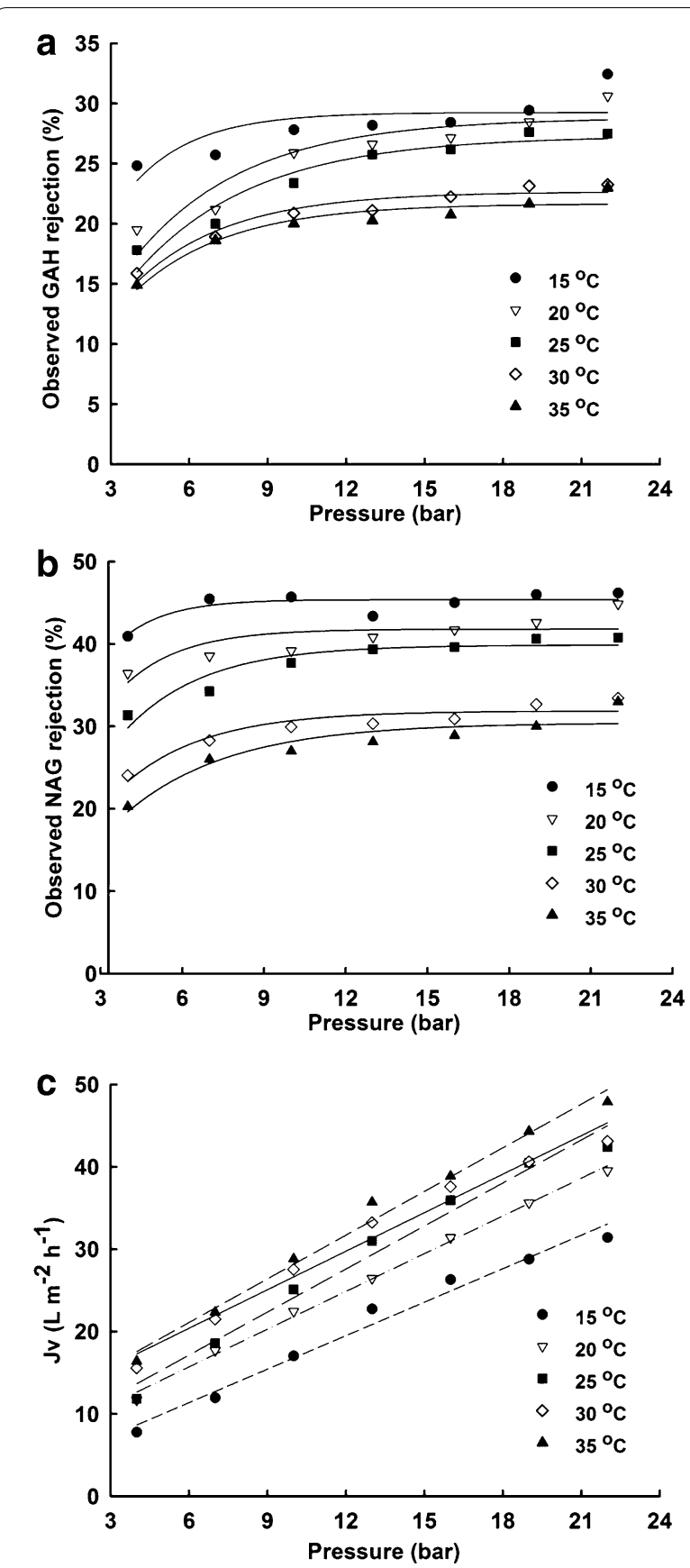

Fig. 6 Effects of different pressures and temperatures on a GAH rejection, $\mathbf{b} N A G$ rejection, c volume flux. The experiments were measured under the condition of mass ratio of GAH:NAG $=1: 2$ (total mass of $7.5 \mathrm{wt} \%)$

provide a good explanation on why both GAH and NAG retentions decrease with increasing operating temperatures (Fig. 6a, b).

Furthermore, the temperature changes calculated molecular diameters as well. For example, Fig. 8b
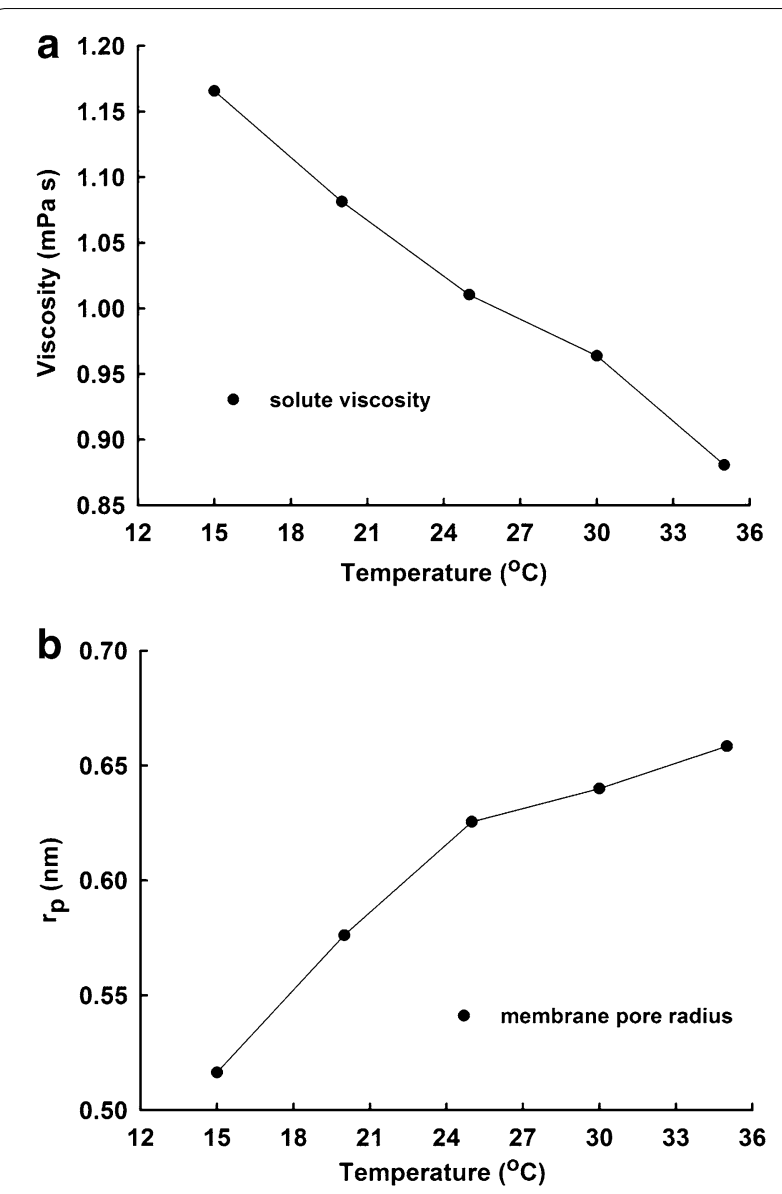

Fig. 7 Effects of different temperatures on a solution viscosity, b membrane pore radius. The experiments were measured under the condition of mass ratio of GAH:NAG $=1: 2$ (total mass of $7.5 \mathrm{wt} \%$ )

illustrates that when the temperature increases from 15 to $35{ }^{\circ} \mathrm{C}$, the calculated molecular diameters for $\mathrm{GAH}$ and NAG increase from 0.61 to $0.62 \mathrm{~nm}$ and from 0.66 to $0.68 \mathrm{~nm}$, respectively. The calculated molecular diameter and increasing temperature showed good exponential relationship. To verify the simulation correctness, according to Eqs. (8) and (10), the relationship between the reflection coefficient obtained from fitting and that obtained from calculation can be estimated. As given in Fig. 9, a significant linear relationship exists between them. This result indicates that the calculated molecular diameter is appropriate to describe the solute retention with temperature variation. Figure 9 also implies that the steric-hindrance effect plays an important role in this separation process.

\section{Influence of different temperatures on the GAH separation factor}

Similarly, the effects of temperature on the GAH separation factor can be obtained from Eq. (12). Figure 10a 


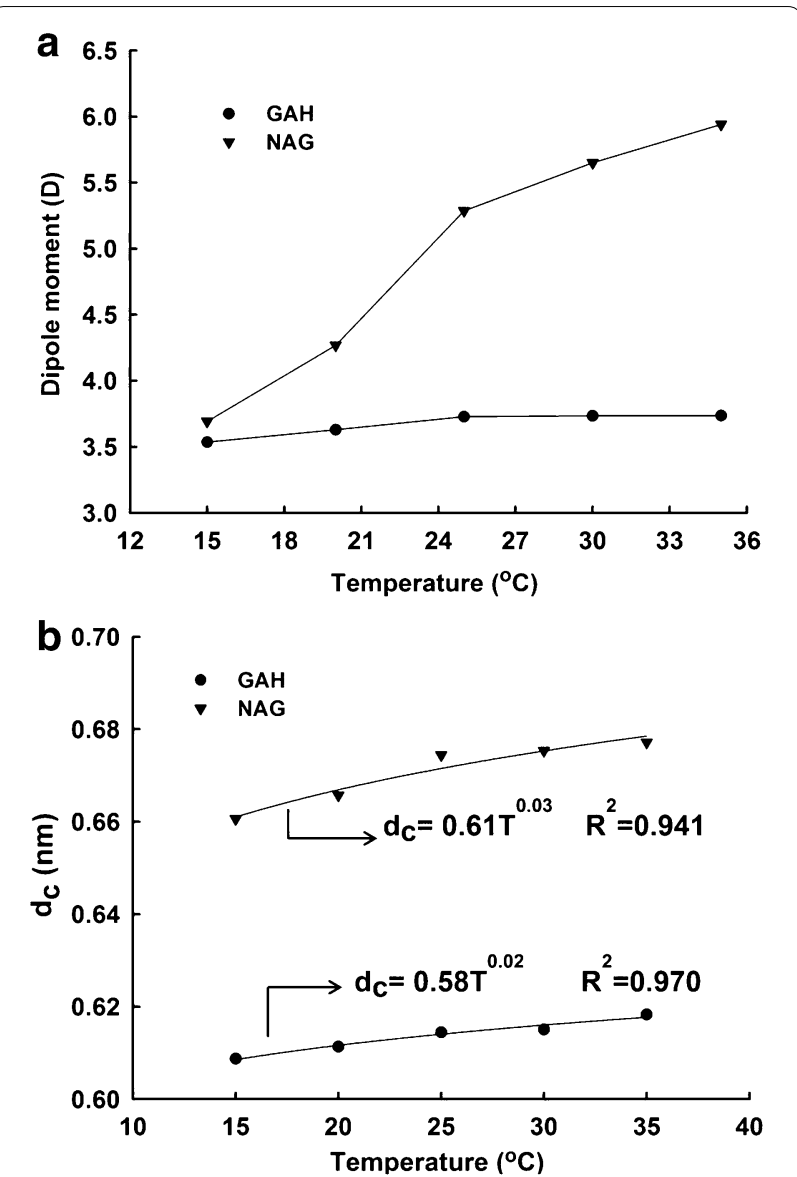

Fig. 8 Effects of different temperatures on a molecular polarities, b calculated molecular diameters of GAH and NAG

illustrates that the GAH separation factors vary slightly with increasing operating pressure, whereas temperature plays a significant role. Higher temperature reduces the GAH and NAG separation performance of the NF membrane. Figure 10b shows that with increasing operating temperature, both GAH and NAG reflection coefficients obtained from Eq. (8) decrease rapidly and their difference value decreases gradually. Given that the reflection coefficient stands for the ultimate rejection of the solute, Fig. 10b explains Fig. 10a suitably as discussed above.

Figure 10c shows that temperature influences both GAH and NAG solute permeability significantly. Compared with the solute reflection coefficient, solute permeability, which also represents the retention performance of membrane for GAH and NAG, shows rising tendency with increasing temperature. For $\mathrm{GAH}$, the solute permeability increases rapidly from $15-20^{\circ} \mathrm{C}$ and then increases slowly when temperature increases from $20-30{ }^{\circ} \mathrm{C}$. Solute permeability of NAG increases slowly from 15 to $30{ }^{\circ} \mathrm{C}$ and then increases rapidly when temperature increases from 30 to $35{ }^{\circ} \mathrm{C}$. Therefore, the permeability

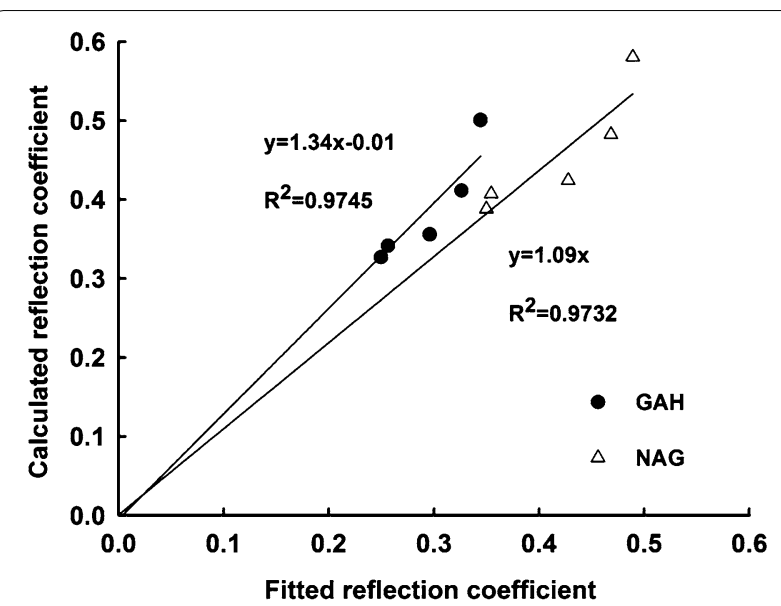

Fig. 9 The relationship between reflection coefficient by fitting and that by calculation for GAH and NAG

difference value between GAH and NAG decreases with increasing temperature. That is why the GAH separation factor decreases with increasing temperature. This result indicates that high temperatures have an adverse effect on the separation for the two mixed solutions.

\section{Influence of different electrolytes on separation performance \\ Influence of different electrolytes on rejections for $G A H$ and NAG}

Figure 11a indicates that different electrolytes significantly affect GAH and NAG retentions. GAH rejection with $\mathrm{MgSO}_{4}$ is higher than those with the other two electrolytes because of the electrostatic repulsion and Donnan equilibrium effects (Luo and Wan 2013). Given that the skin layer of the NF membrane is full of negative charges, the electrostatic repulsion effect becomes stronger caused by $\mathrm{SO}_{4}{ }^{2-}$ in $\mathrm{MgSO}_{4}$. According to the Donnan equilibrium, a counter-ion, which is opposite to the charge on the membrane, is more rejected by the NF membrane to maintain a neutral solution. Furthermore, the electrostatic repulsion effect of divalent ion is stronger than the monovalent ion. Therefore, GAH rejection with $\mathrm{MgSO}_{4}$ is higher than that with $\mathrm{NaCl}$ and $\mathrm{MgCl}_{2}$. According to Luo et al. (2013), as an asymmetry salt, $\mathrm{Mg}^{2+}$ in the solution with $\mathrm{MgCl}_{2}$ weakens the charge effect between the membrane and solute. Hence, GAH rejection with $\mathrm{MgCl}_{2}$ is lower than $\mathrm{NaCl}$.

Figure 11b illustrates the NAG rejections with $\mathrm{NaCl}$, $\mathrm{MgCl}_{2}$, and $\mathrm{MgSO}_{4}$. Figure 11b also shows that different results are obtained with different salts. One explanation for the experimentally determined retention sequence can be found by comparing the diffusion coefficients of the different salts (Schaep et al. 1998) (given in Table 3). 

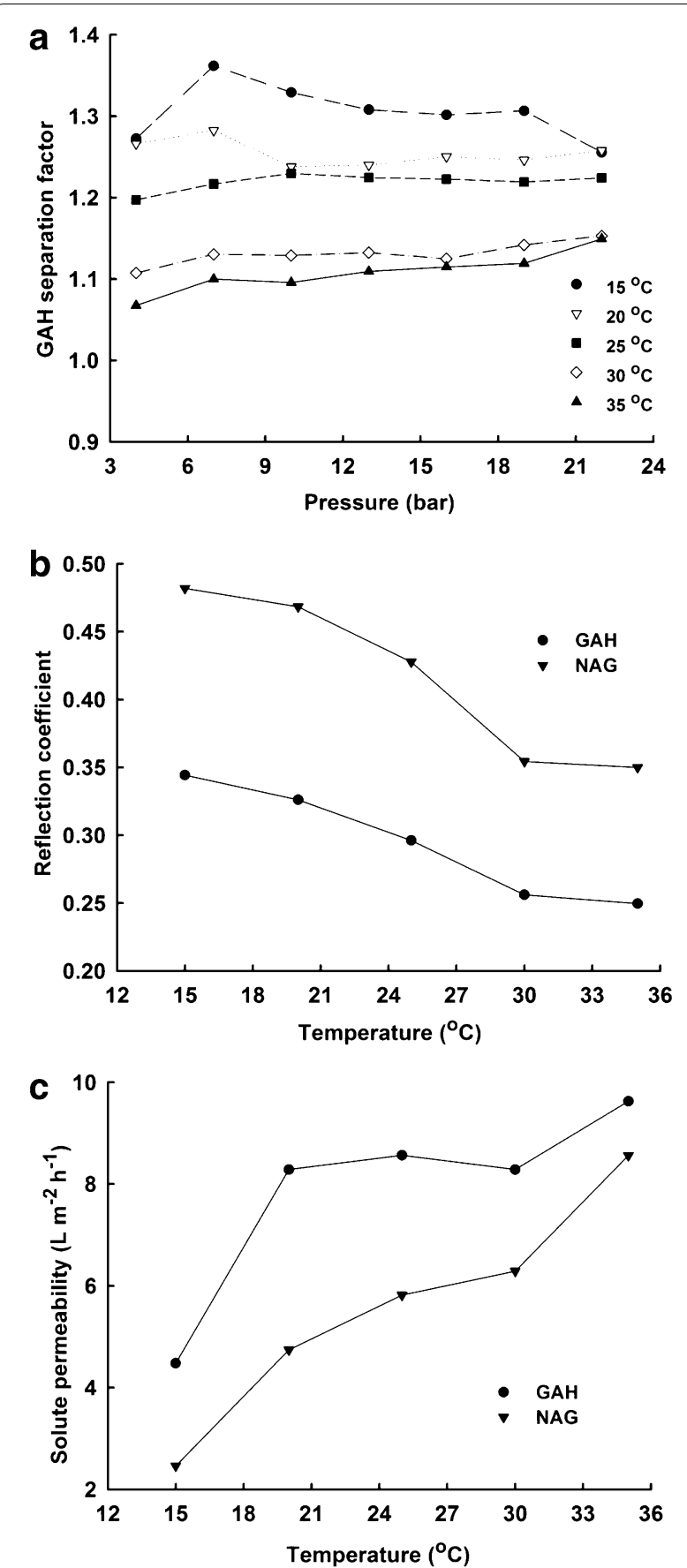

Fig. 10 Effects of different pressures and temperatures on $\mathbf{a} G A H$ separation factor, $\mathbf{b}$ reflection coefficients of $\mathrm{GAH}$ and NAG, $\mathbf{c}$ solute permeability of GAH and NAG. The condition of mass ratio of GAH:NAG was 1:2 (total mass of $7.5 \mathrm{wt} \%$ )

Given that the diffusion coefficient for $\mathrm{NaCl}$ is higher than for $\mathrm{MgSO}_{4}$, which promotes the diffusion of NAG, the rejection of NAG with the $\mathrm{NaCl}$ solution is lower. Similarly, the diffusion coefficient for $\mathrm{MgSO}_{4}$ is smaller
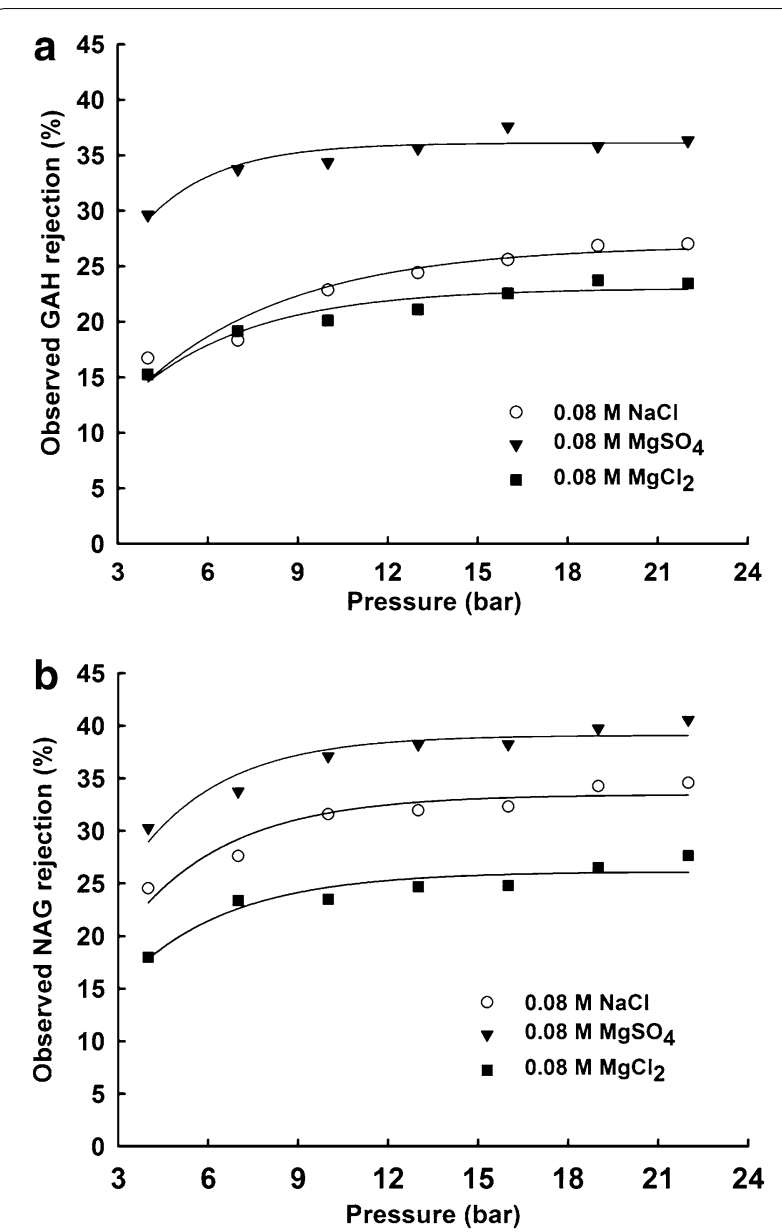

Fig. 11 Effects of different pressures and electrolytes on $\mathbf{a}$ GAH rejection, $\mathbf{b}$ NAG rejection. The results were measured under the condition of mass ratio of GAH:NAG $=1: 2$ (total mass of $7.5 \mathrm{wt} \%$ ), temperature of $25^{\circ} \mathrm{C}$

than $\mathrm{MgCl}_{2}$ and is not good for NAG diffusion. Therefore, the retention of NAG with $\mathrm{MgSO}_{4}$ is higher than that with $\mathrm{MgCl}_{2}$. According to Schaep (Schaep et al. 1998), for the negatively charged membrane, the $\mathrm{MgCl}_{2}$ permeates better than $\mathrm{NaCl}$ because of Donnan exclusion. To some extent, this result is more beneficial to promote NAG diffusion with $\mathrm{MgCl}_{2}$ addition even though the diffusion coefficient of $\mathrm{NaCl}$ is more than that of $\mathrm{MgCl}_{2}$. Hence, NAG rejection with $\mathrm{MgCl}_{2}$ is lower than that with $\mathrm{NaCl}$. The NAG permeability (given in Table 3 ) influenced by three electrolytes is consistent with the above interpretations. The permeability of NAG with $\mathrm{MgCl}_{2}$ is larger than that with $\mathrm{NaCl}$ or $\mathrm{MgSO}_{4}$; therefore, NAG rejection is the lowest with $\mathrm{MgCl}_{2}$ and is the highest with $\mathrm{MgSO}_{4}$. Hence, the retention sequence of NAG is influenced by electrolytes, and the solute diffusion seems to be an important transport mechanism. 
Table 3 Diffusion coefficients of three electrolytes at $25^{\circ} \mathrm{C}$ (Schaep et al. 1998) and permeability of NAG influenced by three electrolytes

\begin{tabular}{|c|c|c|}
\hline Electrolyte & $\begin{array}{l}\text { Diffusion coefficient } \\
\left(10^{-9} \mathrm{~m}^{2} \mathrm{~s}^{-1}\right)\end{array}$ & $\begin{array}{l}\text { Permeability of NAG } \\
\left(\mathrm{L} \mathrm{m}^{-2} \mathrm{~h}^{-1}\right)\end{array}$ \\
\hline $\mathrm{NaCl}$ & 1.61 & 6.52 \\
\hline $\mathrm{MgCl}_{2}$ & 1.25 & 7.69 \\
\hline $\mathrm{MgSO}_{4}$ & 0.85 & 6.22 \\
\hline
\end{tabular}

Influence of different electrolytes on GAH separation factor Figure $12 \mathrm{a}, \mathrm{b}$ shows that the GAH separation factor is close to one and that the rejection difference value is nearly zero with $\mathrm{MgSO}_{4}$, probably because $\mathrm{GAH}$ rejection is almost equal to NAG rejection. Simultaneously, $\mathrm{NaCl}$ makes the $\mathrm{GAH}$ separation factor bigger than the other two salts. Therefore, the GAH separation factor
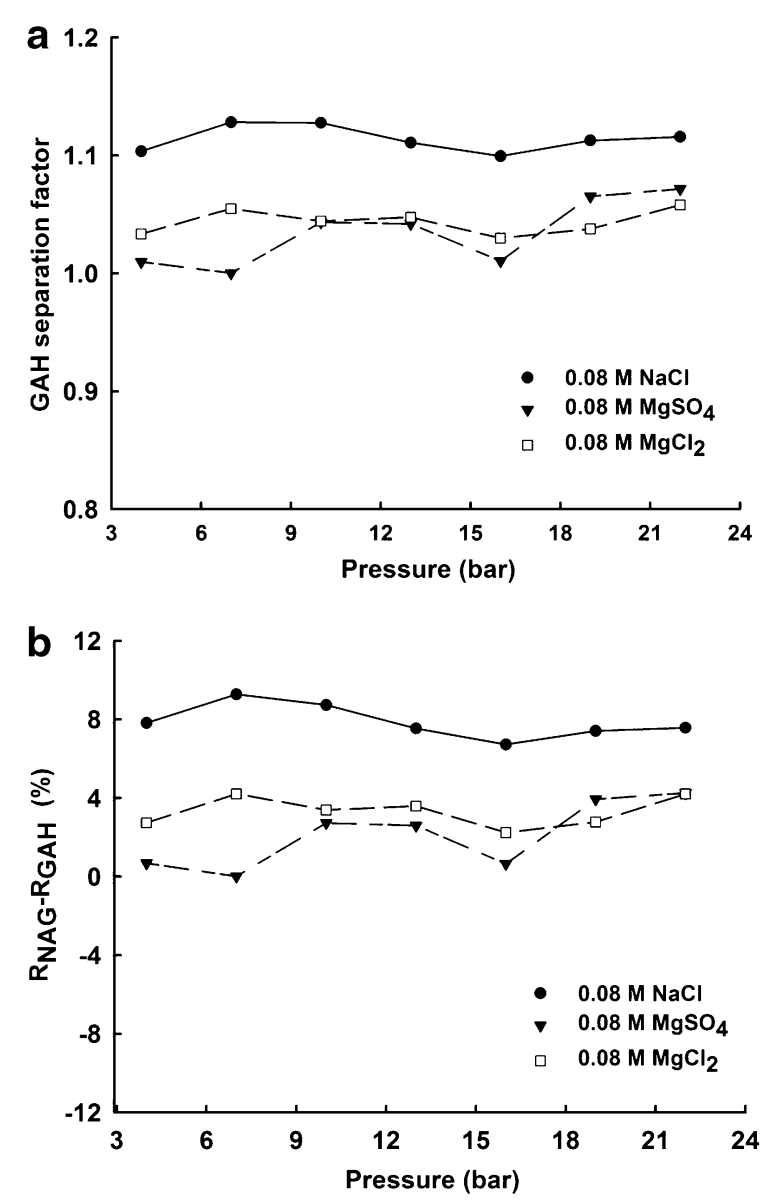

Fig. 12 Effects of different pressures and electrolytes on a GAH separation factor, b difference between observed GAH and NAG retention. The results were measured under the condition of mass ratio of $\mathrm{GAH}: \mathrm{NAG}=1: 2$ (total mass of $7.5 \mathrm{wt} \%$ ), temperature of $25^{\circ} \mathrm{C}$ and the retention difference between GAH and NAG are significantly influenced by different electrolytes.

\section{Conclusions}

NF membrane separation performance was significantly affected by physical conditions in this system. When the mass ratio of GAH:NAG was 1:2, the maximum membrane flux was up to $42.3 \mathrm{~L} \mathrm{~m}^{-2} \mathrm{~h}^{-1}$. Under this condition, the permeability difference obtained from the irreversible thermodynamic model was the largest. Therefore, the GAH separation factor under this condition was up to 1.22. When the temperature was $35{ }^{\circ} \mathrm{C}$, the permeability of $\mathrm{GAH}$ and NAG was 9.6 and $8.7 \mathrm{~L} \mathrm{~m}^{-2} \mathrm{~h}^{-1}$, respectively, and the permeability difference was the minimum. Therefore, lower operation was not good for GAH and NAG separation. Simultaneously, the calculated molecular diameter and increasing temperature showed good exponential relationship, providing supplement for the separation process. After adding salts, by the analysis using the irreversible thermodynamic model, electrostatic repulsion was the essential influencing factor for GAH rejection, and solute diffusion was an important transport mechanism for NAG rejection. With $\mathrm{NaCl}$ addition, the $\mathrm{GAH}$ separation factor was up to 1.13. The explored mechanisms could be used to understand the process of NF separation for monosaccharides with similar molecular weights and provide a certain basis for large-scale separation of chitin derivatives in the future.

\section{Abbreviations}

NF nanofiltration

GAH glucosamine hydrochloride

NAG $\quad N$-acetyl glucosamine

MWCO molecular weight cut-offs

\section{Nomenclature}

$C_{\mathrm{p}} \quad$ solute concentrations in the permeate $\left(\mathrm{g} \mathrm{L}^{-1}\right)$

$C_{\mathrm{b}} \quad$ solute concentrations in the bulk feed $\left(\mathrm{g} \mathrm{L}^{-1}\right)$

$C_{\mathrm{m}} \quad$ solute concentration on the membrane surface $\left(\mathrm{g} \mathrm{L}^{-1}\right)$

$d_{\mathrm{c}} \quad$ calculated molecular diameter $(\mathrm{nm})$

$J_{\mathrm{v}} \quad$ permeat volume flux $\left(\mathrm{L} \mathrm{m}^{-2} \mathrm{~h}^{-1}\right)$

$L_{\mathrm{p}} \quad$ pure water permeability $\left(\mathrm{L} \mathrm{m}^{-2} \mathrm{~h}^{-1} \mathrm{bar}^{-1}\right)$

$k$ mass transfer coefficient $\left(\mathrm{L} \mathrm{m}^{-2} \mathrm{~h}^{-1}\right)$

$\Delta P \quad$ transmembrane pressure (bar)

$P_{\mathrm{s}} \quad$ solute permeability $\left(\mathrm{L} \mathrm{m}^{-2} \mathrm{~h}^{-1}\right)$

$r_{\mathrm{p}} \quad$ mean pore radius $(\mathrm{nm})$

$r_{\mathrm{s}} \quad$ solute radius $(\mathrm{nm})$

$R \quad$ real rejection

$R_{\mathrm{o}} \quad$ observed rejection 


\section{$\Delta \pi \quad$ osmotic pressure difference (bar) \\ $\Delta x / A_{\mathrm{k}}$ the ratio of the effective membrane thickness to membrane porosity $(\mathrm{m})$ \\ $\mu \quad$ solute viscosity (mPa s) \\ $\sigma \quad$ the reflection coefficient}

\section{Authors' contributions}

This paper is the result of joint efforts. Prof. LZ designed the whole experimental plan and confirmed the main objective of this paper. Prof. JZ developed the statistical methods for experimental data. SZ was responsible for the optimization of the nanofiltration technology and the partial investigation of the mechanism in the process. YQ was responsible for the quantification of total sugars. Prof. LJ and Prof. LF helped us complete the paper writing and correcting some grammatical errors in details. All authors read and approved the final manuscript.

\section{Author details}

${ }^{1}$ State Key Laboratory of Bioreactor Engineering, R\&D Center of Separation and Extraction Technology in Fermentation Industry, East China University of Science and Technology, Shanghai 200237, China. ${ }^{2}$ Shanghai Collaborative Innovation Center for Biomanufacturing Technology (SCIBT), Shanghai 200237, China.

\section{Acknowledgements}

This work is financially supported by the National Natural Science Foundation of China (NO.31371725). It is also supported by the National High Technology Research \& Development Program of China (863 Program) (No. SS2014AA021202)

\section{Competing interests}

The authors declare that they have no competing interests.

Received: 3 March 2016 Accepted: 20 June 2016

Published online: 27 June 2016

\section{References}

Aroon MA, Ismail AF, Mastuura T (2010) Performance studies of mixed matrix membrane for gas separation: a review. Sep Purif Technol 75:229-242

Bargeman G, Westerink JB, Miguez OG, Wessling M (2014) The effect of $\mathrm{NaCl}$ and glucose concentration on retentions for nanofiltration membranes processing concentrated solutions. Sep Purif Technol 134:46-57

Ben Amar N, Saidani H, Palmeri J, Deratani A (2009) Effect of temperature on the rejection of neutral and charged solutes by Desal 5 DK nanofiltration membrane. Desalination 246(1-3):294-303

Bowen WR, Mohammad AW, Hilal N (1997) Characterization of nanofiltration membranes for predictive purposes - use of salts, uncharged solutes and atomic force microscopy. J Membr Sci 126:91-105

Brereton KR, Green DB (2012) Isolation of saccharides in dairy and soy products by solid-phase extraction coupled with analysis by ligand-exchange chromatography. Talanta 100:384-390

Bui AV, Nguyen MH (2004) Prediction of viscosity of glucose and calcium chloride solutions. J Food Eng 62(4):345-349

Chen X, Liu L, Li JH, Du GC, Chen J (2012) Improved glucosamine and N-acetylglucosamine production by an engineered Escherichia coli via step-wise regulation of dissolved oxygen level. Bioresour Technol 110:534-538

Chen ZW, Luo JQ, Chen XR, Hang XF, Shen F, Wan YH (2016) Fully recycling dairy wastewater by an integrated isoelectric precipitation-nanofiltrationanaerobic fermentation process. Chem Eng J 283:476-485

Deng MD, Severson DK, Grund AD, Wassink SL, Burlingame RP, Berry A, Running JA, Kunesh CA, Song LS, Jerrell TA, Rosson RA (2005) Metabolic engineering of Escherichia coli for industrial production of glucosamine and $\mathrm{N}$-acetylglucosamine. Metab Eng 7:201-214

Dong HZ, Wang YS, Zhou JC, Xia QM, Jiang LH, Fan LQ, Zhao LM (2014) Purification of DP 6 to 8 chitooligosaccharides by nanofiltration from the prepared chitooligosaccharides syrup. Bioresour Bioprocess 1:1-12
Freger V, Arnot TC, Howell JA (2000) Separation of concentrated organic/inorganic salt mixtures by nanofiltration. J Membr Sci 178(1-2):185-193

Ghfar AA, Wabaidur SM, Yacine Badjah Hadj Ahmed A, Alothman ZA, Khan MR, Al-Shaalan NH (2015) Simultaneous determination of monosaccharides and oligosaccharides in dates using liquid chromatography-electrospray ionization mass spectrometry. Food Chem 176:487-492

Iwasaki K, Matsubara Y (2000) Purification of pectate oligosaccharides showing root-growth-promoting activity in lettuce using ultrafiltration and nanofiltration membranes. J Biosci Bioeng 89(5):495-497

Jian WJ, Siu KC, Wu JY (2015) Effects of pH and temperature on colloidal properties and molecular characteristics of Konjac glucomannan. Carbohydr Polym 134:285-292

Kebria MRS, Jahanshahi M, Rahimpour A (2015) $\mathrm{SiO}_{2}$ modified polyethyleneimine-based nanofiltration membranes for dye removal from aqueous and organic solutions. Desalination 367:255-264

Kedem O, Katchalsky A (1958) Thermodynamic analysis of the permeability of biological membranes to non-electrolytes. Biochim Biophys Acta 27:229-246

Kolfschoten RC, Janssen AEM, Boom RM (2011) Mass diffusion-based Separation of sugars in a microfluidic contactor with nanofiltration membranes. J Sep Sci 34:1338-1346

Koter S (2006) Determination of the parameters of the Spiegler-KedemKatchalsky model for nanofiltration of single electrolyte solutions. Desalination 198(1-3):335-345

Kunz W, Henle J, Ninham BW (2004) 'Zur Lehre von der Wirkung der Salze' (about the science of the effect of salts): Franz Hofmeister's historical papers. Curr Opin Colloid Interface Sci 9(1-2):19-37

Luo JQ, Wan YH (2011) Effect of highly concentrated salt on retention of organic solutes by nanofiltration polymeric membranes. J Membr Sci 372(1-2):145-153

Luo JQ, Wan YH (2013) Effects of pH and salt on nanofiltration-a critical review. J Membr Sci 438:18-28

Mehiguene K, Garba Y, Taha S, Gondrexon N, Dorange G (1999) Influence of operating conditions on the retention of copper and cadmium in aqueous solutions by nanofiltration: experimental results and modelling. Sep Purif Technol 15(2):181-187

Moreno-Vilet L, Bonnin-Paris J, Bostyn S, Ruiz-Cabrera MA, Moscosa-Santillan M (2014) Assessment of sugars separation from a model carbohydrates solution by nanofiltration using a design of experiments (DoE) methodology. Sep Purif Technol 131:84-93

Murthy ZVP, Chaudhari LB (2009) Rejection behavior of nickel ions from synthetic wastewater containing $\mathrm{Na}_{2} \mathrm{SO}_{4}, \mathrm{NiSO}_{4}, \mathrm{MgCl}_{2}$ and $\mathrm{CaCl}_{2}$ salts by nanofiltration and characterization of the membrane. Desalination 247(1-3):610-622

Nakao SI, Kimura S (1982) Models of membrane transport phenomena and their applications for ultrafiltration data. J Chem Eng Jpn 15:200-205

Niewersch C, Meier K, Wintgens T, Melin T (2010) Selectivity of polyamide nanofiltration membranes for cations and phosphoric acid. Desalination 250(3):1021-1024

Paul S, Paul S (2015) Influence of temperature on the solvation of N-methylacetamide in aqueous trehalose solution: a molecular dynamics simulation study. J Mol Liq 211:986-999

Qin JX, Dai XG, Zhou Y, Zhang L, Chen HL, Gao CJ (2014) Desalting and recovering naphthalenesulfonic acid from wastewater with concentrated bivalent salt by nanofiltration process. J Membr Sci 468:242-249

Schaep J, Van der Bruggen B, Vandecasteele C, Wilms D (1998) Influence of ion size and charge in nanofiltration. Sep Purif Technol 14:155-162

Schaep J, Vandecasteele C, Mohammad AW, Bowen WR (2001) Modelling the retention of ionic components for different nanofiltration membranes. Sep Purif Technol 22-23:169-179

Sharma RR, Agrawal R, Chellam S (2003) Temperature effects on sieving characteristics of thin-film composite nanofiltration membranes: pore size distributions and transport parameters. J Membr Sci 223(1-2):69-87

Sjoman E, Manttari M, Nystrom M, Koivikko H, Heikkila H (2007) Separation of xylose from glucose by nanofiltration from concentrated monosaccharide solutions. J Membr Sci 292(1-2):106-115

Spiegler KS, Kedem O (1966) Thermodynamics of hyperfiltration (reverse osmosis): criteria for efficient membranes. Desalination 1:311-326

Tao CZ, Zhang ZT, Wu JW, Li RH, Cao ZL (2014) Synthesis of unnatural N-glycosyl alpha-amino acids via Petasis reaction. Chin Chem Lett 25(4):532-534 
Van der Bruggen B, Schaep J, Wilms D, Vandecasteele C (1999) Influence of molecular size, polarity and charge on the retention of organic molecules by nanofiltration. J Membr Sci 156(1):29-41

Wang KY, Chung TS (2005) The characterization of flat composite nanofiltration membranes and their applications in the separation of Cephalexin. J Membr Sci 247(1-2):37-50

Wang XL, Wang WN, Wang DX (2002) Experimental investigation on separation performance of nanofiltration membranes for inorganic electrolyte solutions. Desalination 145(1-3):115-122

Xie YP, Liu SJ (2015) Purification and concentration of paulownia hot water wood extracts with nanofiltration. Sep Purif Technol 156:848-855

Xing PY, Sun T, Li SY, Hao AY, Su J, Hou YH (2013) An instant-formative heat-set organogel induced by small organic molecules at a high temperature. Colloids Surf A Physicochem Eng Asp 421:44-50

Yaroshchuk AE (2001) Non-steric mechanisms of nanofiltration: superposition of Donnan and dielectric exclusion. Sep Purif Technol 22-23:143-158

Zhao LM, Zhao HF, Nguyen P, Li AR, Jiang LH, Xia QM, Rong Y, Qiu YJ, Zhou JC (2013) Separation performance of multi-components solution by membrane technology in continual diafiltration mode. Desalination 322:113-120
Zhu XL, Cai JB, Yang J, Su QD (2005a) Determination of glucosamine in impure chitin samples by high-performance liquid chromatography. Carbohydr Res 340:1732-1738

Zhu ZZ, Hao ZL, Shen ZS, Chen J (2005b) Modified modeling of the effect of $\mathrm{pH}$ and viscosity on the mass transfer in hydrophobic hollow fiber membrane contactors. J Membr Sci 250(1-2):269-276

Zhu YQ, Liu YF, Li JH, Shin HD, Du GC, Liu L, Chen J (2015) An optimal glucose feeding strategy integrated with step-wise regulation of the dissolved oxygen level improves $\mathrm{N}$-acetylglucosamine production in recombinant Bacillus subtilis. Bioresour Technol 177:387-392

\section{Submit your manuscript to a SpringerOpen ${ }^{\circ}$ journal and benefit from:}

- Convenient online submission

- Rigorous peer review

- Immediate publication on acceptance

- Open access: articles freely available online

- High visibility within the field

- Retaining the copyright to your article 